\title{
Selected in vitro methods to determine antioxidant activity of hydrophilic/lipophilic substances
}

\author{
Aneta Ácsová, Silvia Martiniaková, Jarmila Hojerová \\ Slovak University of Technology in Bratislava, Faculty of Chemical and Food Technology, \\ Institute of Food Science and Nutrition, Department of Food Technology, \\ Radlinského 9, 81237 Bratislava, Slovakia \\ aneta.acsova@stuba.sk
}

\begin{abstract}
The topic of free radicals and related antioxidants is greatly discussed nowadays. Antioxidants help to neutralize free radicals before damaging cells. In the absence of antioxidants, a phenomenon called oxidative stress occurs. Oxidative stress can cause many diseases e.g. Alzheimer's disease and cardiovascular diseases. Therefore, antioxidant activity of various compounds and the mechanism of their action have to be studied. Antioxidant activity and capacity are measured by in vitro and in vivo methods; in vitro methods are divided into two groups according to chemical reactions between free radicals and antioxidants. The first group is based on the transfer of hydrogen atoms (HAT), the second one on the transfer of electrons (ET). The most frequently used methods in the field of antioxidant power measurement are discussed in this work in terms of their principle, mechanism, methodology, the way of results evaluation and possible pitfalls.
\end{abstract}

Keywords: ET methods; HAT methods; in vitro; oxidative stress; total antioxidant activity

\section{Introduction}

Oxidation process is an important part of the metabolic processes in the human body that produce energy to maintain some essential functions. However, it also has side effects as excessive production of free radicals leads to oxidative changes in the body (Nijhawan and Arora, 2019). Natural defense mechanisms of the human body can eliminate/ terminate free radicals. When the production of free radicals prevails over their elimination, they can interact with biological macromolecules (proteins, lipids, carbohydrates) and DNA. The formation of free radicals is initiated by different types of radiation, unbalanced diet, stress, smoking, unhealthy lifestyle, etc. (Klaunig and Wang, 2018). Increased concentration of free radicals in the body can cause skin aging but it can also lead to more serious diseases such as cardiovascular diseases, progressive neurological diseases like Alzheimer's disease, Parkinson's disease, ulcerative colitis and atherosclerosis (Kimáková and Baranovičová, 2015; Yan et al., 2002; Li et al., 2012; Chiavaroli et al., 2011). An antioxidant is generally defined as any substance in low concentration that inhibits or stops the proceeding oxidative damage to important molecules (Yadav et al., 2016). Enzymatic and non-enzymatic antioxidants naturally occur in the human body and counteract the harmful impacts of free radicals (Lobo et al., 2010). An organism can obtain antioxidants from external sources, either in natural form such as from fruits or vegetables, or in synthetic form, for example from nutritional supplements and cosmetics. Vitamin C, coenzyme Q10, beta-carotene, lycopene, uric acid, $\alpha$-tocopherol, selenium, flavonoids and polyphenols are the bestknown natural antioxidants (Farajzadeh, 2016).

In order to compare the effects of individual antioxidants to use them more appropriately, it is necessary to know their antioxidant capacity. Antioxidant capacity of substances is determined by in vivo or in vitro methods (Joseph et al., 2018). The present work is focused on the methods of in vitro determination of antioxidant activity of both hydrophilic and lipophilic samples. In vitro methods can be categorized according to a few criteria depending on the kind of radical (peroxyl radicals, hydroxyl, alkoxy and other) they act, according to the chemical reaction or physical and chemical property of the analyzed substance, etc. (Moukette et al., 2015).

\section{Hydrogen Atom Transfer (HAT) methods}

\section{DPPH (1,1-Diphenyl-2-picrylhydrazyl) assay}

DPPH assay is one of the easiest and most frequently used methods. It has been developed to measure the antioxidant capacity mainly in plants and food extracts (Alshaal et al., 2019). This method uses a commercially available organic compound - 2,2-diphenyl-1-picrylhydrazyl, with the acronym DPPH, generated just before applying the test to a sample. DPPH is a stable chromogen radical caused by electron delocalization in all molecules. This electron delocalization manifests itself in vio- 


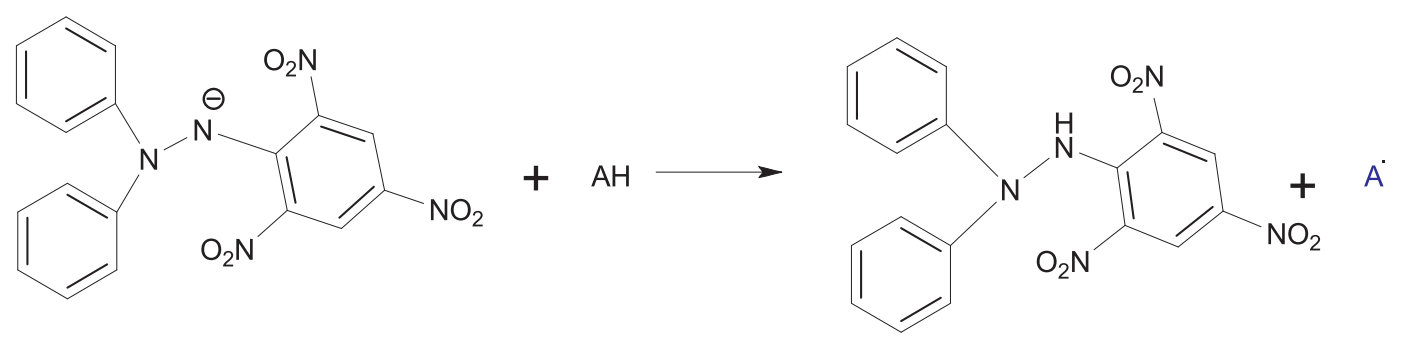

Fig. 1. Reaction of DPPH radical with hydrogen atom donors (Alam et al. 2013).

let in ethanolic/methanolic solution which absorbs radiation with the same wavelength as DPPH radical emits (517 nm) (Pisochi and Negulescu, 2011; Shekhar and Anju, 2014). The DPPH scavenging assay is based on donating a hydrogen atom of antioxidants to 2,2-diphenyl-1-picrylhydrazyl radical to transform it into non-radical form (Fig. 1). The reaction is associated with discoloration of a blue-colored solution to pale yellow as a sign of the potential antioxidant activity of the sample (Alam et al., 2013).

According to Alam et al., 2013, the sample is diluted with a solvent depending on the character of the sample and then mixed with the DPPH solution. Such prepared mixture is first incubated for $30 \mathrm{~min}$ at $25^{\circ} \mathrm{C}$ and after an aliquot of the incubated solution is added to the spectrophotometer, the absorbance at $517 \mathrm{~nm}$ is measured (Moran-Palacio et al., 2014). The percentage of DPPH radical scavenging $(\mathrm{ESC}=$ experimental scavenging capacity) is calculated using Eq. 1:

$$
E S C=\frac{A_{b r}-A_{a r}}{A_{b r}} \times 100 \%
$$

where $A_{b r}$ is the absorbance measured before the reaction and $A_{a r}$ after the reaction. The antioxidant activity is then expressed as the amount of antioxidant sample needed to decrease the synthetic DPPH radical's concentration to $50 \%$ (also known as $\mathrm{EC}_{50}$ ) (Pisochi and Negulescu, 2011). In addition, the power of the antiradical potential can also be characterized by the $\mu \mathrm{M}$ Trolox equivalent for the initial amount of fresh mass $(\mu \mathrm{M} / \mathrm{g}$ FM).

Although the DPPH method is simple, it is very sensitive and easily influenced by various factors such as the presence and concentration of hydrogen atom, amount of used solvent, presence of catalytically acting metal ions and freshness of the DPPH solvent (Zhong and Shahidi, 2015). What makes the DPPH radical reactive is the presence of nitrogen atom with an unpaired electron in the center of the DPPH molecule (Yeo and Shahidi, 2019). However, this presents a steric limitation for large molecules as they cannot inhibit the radical portion of the DPPH radical located in the center (Holtz, 2009). Smaller molecules able to effectively overrun the steric barrier in the DPPH molecule include ascorbic acid and simple phenols. The reaction between phenol and the radical can be slowed down if side chains or acid groups are connected on the aromatic rings of phenols (Schaich et al., 1985). Yeo et al. (2019) studied limitations of the DPPH scavenging ability of pigments and dyes from plant extracts. The limiting factor was that dyes and pigments reached their absorption maximum at the same wavelength as DPPH radicals. To overcome this limitation, different equipment and a different antioxidant activity of dyes determination method, such as electron paramagnetic resonance (EPR) spectroscopy, was used. Values obtained by the EPR spectroscopy differ by more than $16 \%$ from those obtained by the standard spectrophotometric DPPH method.

\section{TRAP (Total peroxyl radical-TRapping Antioxidant Potential) assay}

TRAP method proposed by Wayner et al. in 1985 was used to quantify the antioxidant capacity in human blood plasma. Since then it has undergone some modifications but its principles have been preserved. The effect of either free radicals or the presence of antioxidants on the fluorescence generated by the fluorescent molecule is monitored. This method monitors the amount of consumed oxygen during lipid peroxidation caused by the thermal brake down of substances such as ABAP (2,2'-Azobis(2-amidinopropane) (Figure 2) or AAPH (2,2' -azobis(2-methylpropionamidine) dihydrochloride) into simpler matters (Martín et al., 2017).

The TRAP test is often applicable in the determination of the antioxidant activity of biological samples as human plasma or natural samples as plant extracts (Denardin et al., 2015). The TRAP method is sensitive to temperature and $\mathrm{pH}$ changes (Martín et al., 2017). Denardin et al. (2015) studied fruit extracts for their non-enzymatic antioxidant capacity using this antioxidant method. The peroxy radical was generated by mixing a solution of AAPH with Luminol to enhance chemiluminescence. A sample was added to the peroxy radical and the absorbance after 30 minutes of incubation was measured. 


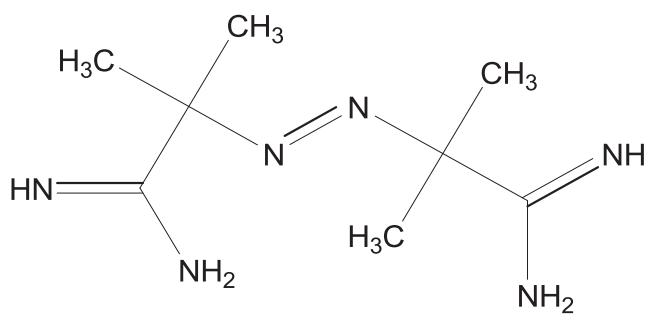

Fig. 2. Chemical structure of ABAP.

They concluded that fruits with higher content of phenols also have higher antioxidant activity. Moreover, although Brazilian plant called Butia had high content of the well-known antioxidant - ascorbic acid, its power to fluorescence quenching was lower than in other plants. This assay is very suitable for biological samples such as plasma, urine and others because they are able to perfectly react and combine with peroxy radicals (Munialo et al., 2019).

\section{ORAC (Oxygen Radical Absorbance Capacity) assay}

Advantages of the ORAC test include high adaptability to antioxidants, biological samples and foods and the capability of assaying antioxidant potential of non-protein samples using a wide range of extraction agents (Prior, 2015). The reaction is conceptually simple but difficult in practice. The reactions start with heating of azide compounds to release nitrogen gas and generate two radicals $\left(\mathrm{R}^{*}\right)$ (equation 2). During the radical generation, it is very important to keep the optimal heating temperature to ensure total azide decomposition. If the required temperature is not maintained, unclear and incomparable results are obtained (MelladoOrtega et al., 2017).

The interaction between $\mathrm{R}^{\bullet}$ and sufficient oxygen leads to the formation of peroxy radicals, ROO (equation 3) which can either attack near colored or fluorescent molecules (equation 4) or react with antioxidants (equations 5, 6). Fluorescence is lost when a fluorescent molecule is attacked by peroxyl radicals. The less antioxidant participates in the reaction, the higher the decomposition of the fluorescent molecule and the higher the fluorescence signal loss (Schaich et al., 2015).

$$
\begin{gathered}
\mathrm{R}-\mathrm{N}=\mathrm{N}-\mathrm{R} \stackrel{\Delta t}{\rightarrow} \mathrm{N}_{2}+2 \mathrm{R}^{\bullet} \\
\mathrm{O}_{2}+2 \mathrm{R}^{\bullet} \rightarrow \mathrm{ROO}^{\bullet} \\
\mathrm{ROO}^{\bullet}+\text { target molecule } \rightarrow \\
\rightarrow \mathrm{ROOH}^{\circ} \text { oxidized molecule } \\
\mathrm{ROO}^{\bullet}+\mathrm{AH} \rightarrow \mathrm{ROOH}+\mathrm{A}^{\bullet} \\
\mathrm{ROO}^{\bullet}+\mathrm{A}^{\bullet} \rightarrow \mathrm{ROO}-\mathrm{A}
\end{gathered}
$$

Fluorescence intensity over time is monitored via the antioxidant activity evaluation. Trolox is used as a standard for evaluation where its different concentrations are used to obtain a fluorescence intensity time-curve and compared with the test samples. Thus, quantification of the ORAC test is based on the evaluation of the area under the timecurve (AUC) (Schaich et al., 2015).

\section{CB (Crocin Bleaching) assay}

Crocin bleaching assay is suitable for the antioxidant potential determination of both lipophilic and hydrophilic samples (Yeum et al., 2004). This method uses crocin (Figure 3) as a substance competing with the added antioxidant and AMVN (2,2'-azobis-2,4-dimethylvaleronitrile) or AAPH (2.2'-azobis-2-amidinopropane: $\mathrm{R}-\mathrm{N}=\mathrm{N}-\mathrm{R}$ ) as the source of free radicals. AAPH is generally used for cuvette spectrophotometer, while AMVN is more frequently used for a microplate spectrophotometer. The degree of crocin whitening by a potential antioxidant is measured at $450 \mathrm{~nm}$ (Prieto et al., 2015; Sotto et al., 2018).

Interaction between free radicals and crocin polyene structure results in disruption of the conjugated system, which corresponds to crocin bleaching. The disruption of the crocin polyene structure depends on the form of the radical with which it reacts. Conversely, hydroxyl type of radicals cannot be used here due to their high reactivity with other organic substances (Ordoudi and Tsimidou, 2006).

Peroxyl radicals are formed in two steps; the first one is thermal degradation of the initiator (equation 7) and the second one is the reaction with oxygen to generate peroxyl radicals (equation 8).

$$
\begin{gathered}
\mathrm{NR}=\mathrm{NR} \stackrel{\Delta t}{\rightarrow} 2 \mathrm{R}^{\bullet}+\mathrm{N}_{2} \\
\mathrm{R}^{\bullet}+\mathrm{O}_{2} \leftrightarrow \mathrm{ROO}^{\bullet} \\
\mathrm{ROO}^{\bullet}+\text { crocin } \rightarrow \mathrm{ROOH}+\text { crocin }^{\bullet} \\
\mathrm{ROO}^{\bullet}+\mathrm{AH} \rightarrow \mathrm{ROOH}+\mathrm{A}^{\bullet} \\
\mathrm{A}^{\bullet}+\text { crocin } \rightarrow \mathrm{AH}+\text { crocin }
\end{gathered}
$$

Subsequently, radicals cause crocin bleaching (equation 9) leading to the solution color loss. More mechanisms of reaction of the resulting radical with an antioxidant can be considered depending on the type of antioxidant. In case of $\beta$-carotene or other carotenoid antioxidants, very common mechanism is hydrogen atom abstraction (equation 10). Other radicals are also formed as intermediates which are further bound to the crocin structure and the bleaching process begins to cycle (Ordoudi 
<smiles>CC(/C=C/C=C(\C)C(=O)OC1OC(COC2OC(CO)C(O)C(O)C2O)C(O)C(O)C1O)=C\C=C\C=C(C)\C=C\C=C(/C)C(=O)OC1OC(CO)C(O)C(O)C1OCC1OC(CO)C(O)C(O)C1O</smiles>

Fig. 3. Chemical structure of crocin.

and Tsimidou, 2006). Bleaching reaction rates of antioxidant and sample without antioxidant were calculated simultaneously by monitoring the decrease in absorbance at $450 \mathrm{~nm}$ and a suitable temperature. Trolox, synthetic analogue of vitamin $\mathrm{E}$, can be used as a reference at the same conditions as the analyzed samples. Then, the overall concentration ratio (result) of crocin bleaching calculated as crocin inhibition in percentage or as relative constant of bleaching process rate (Bortolomeazzi et al., 2007).

Disadvantages of this method include the low reproducibility, sample preparation by pre-heating and strict compliance of working temperature and $\mathrm{pH}$, differences in reagent preparation and problematic quantification of results (Prior, 2015).

TOSC (Total Oxyradical Acavenging Capacity) assay The research groups of Regoli and Winston (1998) were the first ones interested in quantification of total oxyradical scavenging capacity by antioxidants (Franzoni et al., 2017). The TOSC method has a wide application as it can be used for one-component antioxidants but also in complexes such as tissues or biological fluids in the body. Moreover, large deviations of both hydrophilic and lipophilic substances cannot be observed despite their sometimes lower concentration range (Lichtenthäler et al., 2003). The TOSC test is based on the reaction between free radicals, especially oxyradicals (peroxyl, hydroxyl, and peroxynitrite radicals) (Ojha et al., 2018), and $\alpha$-keto- $\gamma$-methiolbutyric acid (KMBA) to form the simplest organic compound known as ethene (equation 12). Each radical is obtained in a different way. While generation of peroxyl radicals and peroxynitrite requires heat processing of
2,2' 'azobis(2-methylpropionamidine) dichloride (ABAP) and 3-morpholinosydnonimine N-ethylcarbamide, respectively, the formation of hydroxyl radicals runs through the Fenton reaction (Garrett et al., 2010).

$\mathrm{CH}_{3} \mathrm{~S}-\mathrm{CH}_{2}-\mathrm{CH}_{2}-\mathrm{CO}-\mathrm{COOH}+\mathrm{O}^{\circ} \mathrm{OH}(\mathrm{R}) \rightarrow$

$\rightarrow 1 / 2\left(\mathrm{CH}_{3} \mathrm{~S}\right)_{2}+\mathrm{RHOO}^{-}+\mathrm{CO}_{2}+\mathrm{CH}_{2}=\mathrm{CH}_{2}$

As mentioned above, when radicals interact with $\mathrm{KMBA}$, ethene in gaseous state is formed and its formation can be monitored by gas chromatography. The potential antioxidant is as strong as it can prevent oxidative decomposition of the acid in the presence of oxyradicals (Regoli, 2000).

\section{DMPD (N1,N1-DiMethyl-1,4-PhenyleneDiamine)} assay

Also in case of DMPD assay, oxidants in the samples are reduced and the color change is evaluated spectrophotometrically (equation 14). First, the DMPD $^{*+}$ radical is formed by mixing a solution of DMPD (Figure 4) in acetate buffer and ferric chloride $\mathrm{FeCl}_{3}$ (equation 13) (Jiang et al., 2019). The prepared red colored solution of the DMPD cation is allowed to stand at laboratory temperature for 12 hours before being used to assess antioxidant activity of the sample (Askin, 2018). Oxidative status of the substance with DMPD ${ }^{\circ+}$ is readable at $515 \mathrm{~nm}$ (Kamer et al., 2019; Goosen, 2018).

$$
\begin{gathered}
\operatorname{DMPD}_{\text {(colorless) }}+\operatorname{oxidant}\left(\mathrm{Fe}^{3+}\right)+\mathrm{H}^{+} \rightarrow \\
\rightarrow \mathrm{DMPD}^{\cdot+}{ }_{\text {(purple) }} \\
\mathrm{DMPD}^{\cdot+}{ }_{\text {(purple) }}+\mathrm{AOH} \rightarrow \mathrm{DMPD}^{+}{ }_{\text {(colorless) }}+\mathrm{AO}
\end{gathered}
$$

Advantages of this method include short reaction time, long life time of the chemical reaction and 
low financial costs. These advantages are the most important criteria for compatible global assays (Rodriguez-Nogales et al., 2011). Each method has its advantages and disadvantages; for example, lower applicability for hydrophobic substances as the reproducibility of the method decreases with the increasing hydrophobicity. Another serious disadvantage is in the compatibility of several solvents. The choice of methanol as a solvent for DMPD is not very suitable (Singh and Singh, 2008).<smiles>CN(C)c1ccc(N)cc1</smiles>

Fig. 4. Chemical structure of DMPD.

\section{Single Electron Transfer (SET) methods}

\section{ABTS (2,2'-azinobis(3-ethylbenzothiazol-6-sulpho- nate)) assay}

The first method based on single electron transfer described in this work is an ABTS decolorization test. The application of this method is wide due to its numerous modifications and it can be applied in antioxidant activity determination in both pure lipophilic and hydrophilic antioxidants, including carotenoids, flavonoids (Granato et al., 2018) and food samples, beverages and plasma antioxidants<smiles>CCn1/c(=N/N=c2\sc3cc(S(=O)(=O)O)ccc3n2CC)sc2cc(S(=O)(=O)O)ccc21</smiles>

Fig. 5. Chemical structure of ABTS.

(Ferrante et al., 2019), because this radical is soluble in water but also in several organic solvents (Re et al., 1999).

The ABTS $^{\bullet+}$ (2,2' -azinobis-(3-ethylbenzothiazoline-6-sulfonic acid)) radical can be generated in several different ways: less often electrochemically, enzymatically in case of biologic samples and chemically used potassium persulfate (Figure 6) or peroxide radicals. The original blue-green solution is decolorized while the decolorization is adequate to the power of the substance antioxidant activity (Floegel et al., 2011). An advantage of this method is that it has a short analysis time and synthetic $\mathrm{ABTS}^{\cdot+}$ radical has a characteristic absorption spectrum with maximum peaks in the range of 414 to $815 \mathrm{~nm}$, which is an advantage in case of colored compounds (Lim et al., 2019; Wan et al., 2018).

Mixture of potassium persulfate with ABTS substance in the ratio $0.5: 1$ has to be maintained for at least 6 hours. A shorter interaction may result in partial oxidation, leading to unstable $\mathrm{ABTS}^{\bullet+}$. The radical is stable for up to two days when stored in a container without light and oxygen at room temperature. As with previous methods, it is impor-<smiles>CCn1/c(=N/N=c2\sc3cc(S(=O)(=O)O)ccc3n2CC)sc2cc(S(=O)(=O)O)ccc21</smiles><smiles></smiles>

Fig. 6. Generation of ABTS cation radical (Zou et al. 2019; custom modification). 
tant to differentiate the reaction time intervals at which $\mathrm{ABTS}^{\circ+}$ and the analyzed sample react (Re et al., 1999); which is 6 minutes according to $\mathrm{Re}$ et al. (1999), Pérez-Jiménez et al. (2008) and Van den Berg et al. (1999) while Alam et al. (2013) considered only a 5 min interval when determining the antioxidant activity of plant extracts. Pérez-Jiménez et al. (2008) determined polyphenols (Coffee acid, Ferulic acid, Gallic acid, Quercetin and Rutin) in extracts of white and red grape, which represents an excellent source of antioxidants. Re et al. (1999) investigated anthocyanins and flavonoids. Van den Berg et al. (1999) investigated $\alpha$-tocopherol, $\beta$-carotene and Vitamin $\mathrm{C}$ and their combinations. Determination of antioxidant activity such as DPPH but also ABTS methods are usually performed using a spectrophotometer. A disadvantage is that it is not possible to separate the antioxidants present in the samples as complex matrices (Alam et al., 2013). Ma et al. (2019) proposed using liquid chromatography or capillary electrophoresis as a complementary method for online DPPH or ABTS assays to make these spectrophotometric methods full-fledged and more informative (Koleva et al., 2000; Murauer et al., 2017).

\section{TEAC (Trolox Equivalent Antioxidant Capacity) assay}

TEAC is a commonly used assay to assess the amount of radicals that can be scavenged by antioxidants able to offer their electrons. The TEAC method is very closely related to the ABTS method (Zablocka et al., 2019). The name of the method indicates that the main component is Trolox with a chemical identifier as 6-hydroxy-2,5,7,8-tetramethylchroman-2-carboxylic acid (Figure 7). It is easy to convert absorbances obtained from a spectrophotometer into the antioxidant activity of Trolox and thus it is used as the comparing standard substance for measurements. Trolox is a chromanol, which means that it is a member of the phenols group and a monocarboxylic acid. For pure substances, TEAC is defined as the millimolar concentration of Trolox corresponding to the antioxidant activity of the test sample at the concentration of $1 \mathrm{mmol} / \mathrm{L}$. In case of mixtures and complex samples, the Trolox substance amount corresponds to antioxidant activity of $1 \mathrm{~g}$ or $1 \mathrm{~mL}$ of the sample (Obón et al., 2005).

This method was developed by Miller et al. (1993) and it can be used spectrophotometrically with both synthetic radicals of DPPH and ABTS. The colored complex of radicals in the presence of a sample containing substances with a potential antioxidant, is discolored. Depending on the rate of solution discoloration, it is possible to determine the sample activity at a suitable wavelength. TEAC assay can also be adapted and automated to flow injection and microplates techniques (Zhong and Shahidi, 2015).<smiles>Cc1c(C)c2c(c(C)c1O)CCC(C)(C(=O)O)O2</smiles>

Fig. 7 Chemical structure of Trolox.

This method has many modifications. For example, Pérez-Burillo et al. (2018) introduced two types of the TEAC method - TEACOH, and TEACAAPH. TEACOH determines the quenching effect of hydroxyl radicals $\left(\mathrm{OH}^{*}\right)$ with foodstuffs, while TEACAAPH analyzes the quenching effect of $\mathrm{AAPH}^{\circ}$ radicals with beverages and different foods (Obón et al., 2005).

\section{FRAP (Ferric Reducing Ability of Plasma) assay}

Ferric reducing/antioxidant activity is a primary method for assessing the total antioxidant capacity. The FRAP method is sensitive, cheap and fast (Choy et al., 2000). Ferric ion of TPTZ (2,4,6-Tri(2-pyridyl)1,3,5-triazine) reduction by an antioxidant (Figure 8) in the presence of acetate buffer causes the formation of a blue colored ferrous-tripyridyltriazine com-

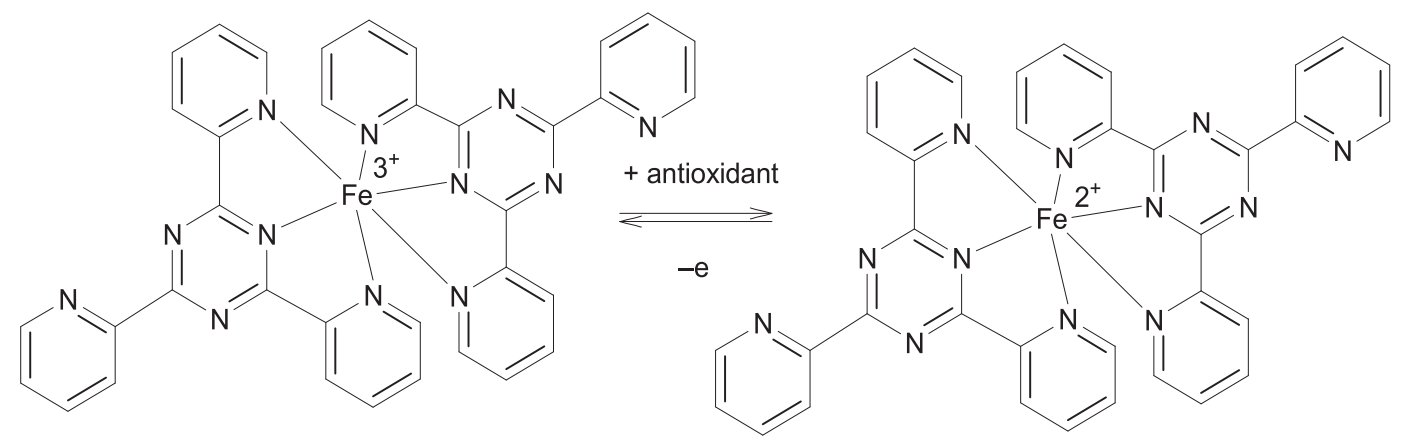

Fig. 8. Chemical reaction of TPTZ and antioxidant (Shalaby, 2013). 
plex. The reduction is indicated by the formation of intense blue color with an absorption maximum at 593 nm (Benzie and Strain, 1999; Seesom et al., 2018). Basically, the FRAP value is evaluated as the reduction power of $\mathrm{Fe}$ (III) to $\mathrm{Fe}(\mathrm{II})$ (Haida and Hakiman, 2019; Ononamadu et al., 2019). Another evaluation method employs equivalent concentration of Trolox to the initial sample amount (Lachowicz et al., 2018). The FRAP working solution is made under heating $\left(37^{\circ} \mathrm{C}\right)$ when acetate buffer, TPTZ and $\mathrm{FeCl}_{3} \cdot 6 \mathrm{H}_{2} \mathrm{O}$ are mixed together in the ratio of 10:1:1 (Benzie and Strain, 1999). Ideally, the solution is yellow if there is no reduction of ferric ions. Fresh frap working solution should be used in each experiment. Subsequently, optimal amount of the working solution is mixed with an aliquot and the change in absorbance can be seen at $593 \mathrm{~nm}$ after a 30 minutes interaction of the FRAP reagent with the sample (Oribayo et al., 2018).

Torre et al. (2015) introduced a modified microplate-based FRAP method (mFRAP) which leads to improved sample throughput compared to the manual FRAP assay. The main difference is that microplates are used instead of glass cuvettes and smaller volumes of samples are needed to determine the antioxidant activity. Burnaz and coworkers found that online or offline association of FRAP antioxidant evaluation with chromatographic separation methods represents a significant improvement in the awareness of antioxidant contributions of individual compounds of the complex samples. The HPLC method is one of the most used pre-treatment methods for the samples further determined by the FRAP method. The lengthy pre-treatment processes sometimes last for days, which is a big disadvantage. Shi et al. (2019) eliminated the pre-treatment by introducing of a microcolumn packed with a very small amount of solid sample, also the system of antioxidant evaluation is faster.

\section{CUPRAC (CUPRic Antioxidant Capacity) assay}

Another method for antioxidant capacity in vitro determination is the CUPRAC method, where the redox properties of copper are the guiding principle. It is used to determine both water- and oilsoluble substances in the physiological $\mathrm{pH}$ range (Sundararajan and Ilengesan, 2018; Drouet et al., 2018), providing a great advantage over FRAP, where acetate buffer is used to prepare the chemical reagent causing an acidic environment (Gupta, 2015).

In this method, neocuproine is used as the chelating agent which, when reacted with an antioxidant, yields a CUPRAC chromophore. CUPRAC chromophore is maximally detectable at $490 \mathrm{~nm}$. The chelating agent has to be prepared in the correct ratio of neocuproine:copper(II)chloride:ammonium acetate and protected from unacceptable environmental factors as air and daylight (Celik, 2019).

The reaction most often proceeds at $\mathrm{pH} 7$ for 30 minutes. In case of antioxidants which react slower and harder, these need to be heated at the temperature of $\sim 50{ }^{\circ} \mathrm{C}$ for $20 \mathrm{~min}$ to improve their color visualization (Apak et al., 2008). The resulting color is orange-yellow. The antioxidant capacity of compounds is most often expressed as Trolox equivalents (TEAC values) (Alam et al., 2013).

The CUPRAC method is used to measure the antioxidant level of total phenolics, separately flavonoids, vitamins, but also synthetic antioxidants to compare them (Gupta, 2015). As in many other methods, a spectrophotometer is required for the measurement, which is one of the disadvantages. Results obtained by combination of CUPRAC and TEAC assay modified by Akar et al. (2019) were differentiated with the original spectrophotometrically obtained TEAC values. Another modification may be the use of a drip of the reaction sample for TLC chromatography in combination with CUPRAC and subsequent subtraction of probes in the image program.

\section{FC (Folin-Ciocaltueau) assay}

The Folin-Ciocalteu method was originally developed for the determination of protein complexes, specifically for tyrosine which contains a phenolic group in the $\mathrm{FC}$ reagent molecule.

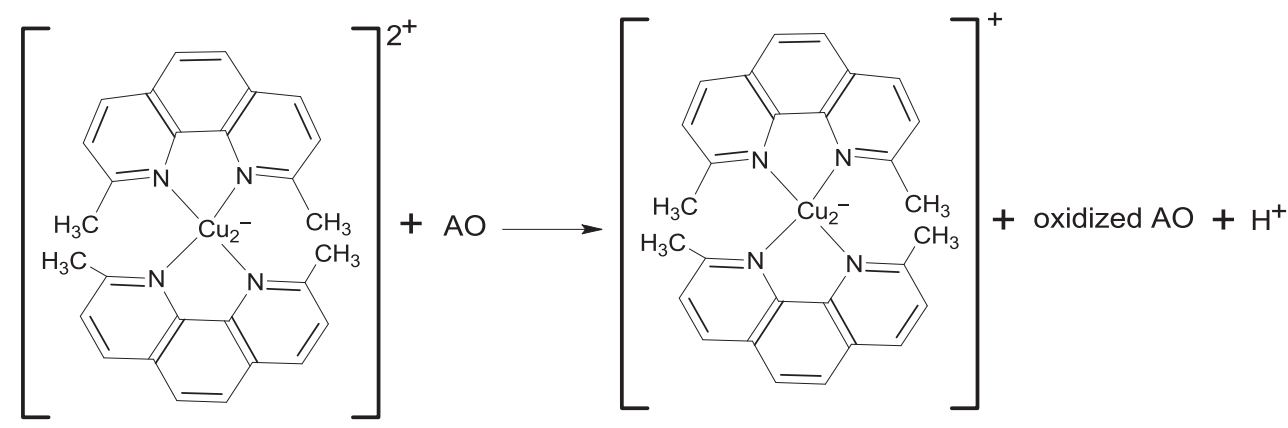

Fig. 9. Reaction scheme for the CUPRAC assay. 
Thanks to Singleton et al. (1999), the FC method has evolved to determine total phenols in other sample matrices, especially in wine (Everette et al., 2010). However, it has been shown that the reaction of an antioxidant with the FC reagent results in an increased electron transfer from the antioxidant compared to the hydrogen atoms, contributing to the degree of antioxidant activity evaluation of potential antioxidants (Abramovič et al., 2018). The principle of this method is reducing the FC reagent composed of a mixture of phosphotungstic acid and phosphomolybdenic acid to a mixture of blue tungsten oxides and molybdenum oxides by oxidizing phenols present in the sample. The blue color is a result of $\mathrm{Mo}(\mathrm{VI})$ reduction to $\mathrm{Mo}(\mathrm{V})$ and it shows maximum light absorption in the wavelength range of 750-760 nm (Figure 10) (Ainsworth and Gillespie, 2007). The FC chromophore, namely molybdo-tungsto-phosphate polyanion $\left(\mathrm{PMoW}_{11} \mathrm{O}_{4} \mathrm{O}_{4}^{-}\right)$, shows affinity for hydrophilic greater extent as its negative charges are able to interact with molecules of water in a much more than with organic solvents. That is why the conventional FC test is mainly used in hydrophilic phases and it is not suitable for lipophilic substances determination in a modified form. Determination of lipophilic substances can be adapted by a modification of the original FC method - in isobutylalcohol (Berker et al., 2013). The difference between a conventional FC test and this modified one is that the $\mathrm{FC}$ reagent is prepared in isobutanol (Minussi et al., 2003) and the test is realized in the presence of $\mathrm{NaOH}$, thereby inducing suitable conditions for both types of substances (Wong et al., 2006).

The FC reagent is prepared by dissolving sodium molybdate $\left(\mathrm{Na}_{2} \mathrm{MoO}_{4} \cdot 2 \mathrm{H}_{2} \mathrm{O}\right)$ and sodium tungstate $\left(\mathrm{Na}_{2} \mathrm{WO}_{4} \cdot 2 \mathrm{H}_{2} \mathrm{O}\right)$ in deionized water. The mixture is then acidified with concentrated $\mathrm{HCl}$ and $85 \%$ phosphoric acid. Such prepared acidified solution is boiled for 10 hours and $\mathrm{Li}_{2} \mathrm{SO}_{4} \cdot 4 \mathrm{H}_{2} \mathrm{O}$ is then added at room temperature. The resulting solution can be yellow (Huang et al., 2005). In this case, the reducing agent is molybdate which should have stronger redox properties than tungsten (equation 15). In the reaction with an antioxidant, blue color exhibits maximum light absorption in the wave- length range of $750-760 \mathrm{~nm}$ and its intensity is directly proportional to the total amount of phenols initially present in the sample (Sánchez-Rangel et al., 2013).

$$
\begin{gathered}
\mathrm{Mo}^{\mathrm{VI}}+\mathrm{e}^{-}(\text {from phenolic } \\
\text { or another reduced substance }) \rightarrow \mathrm{Mo}^{\mathrm{V}}
\end{gathered}
$$

The Folin-Ciocalteu assay has been widely used to determine the absolute phenolic content and antioxidant potential of plant-derived food and biological samples (Huda-Faujan et al., 2009; Al-Farsi et al., 2018; Shalaby, 2013). The in vivo results showed a strong indirect correlation between the phenol content and the prevention of serious diseases such as neurological or cardiovascular disease and DNA damage (Lamuela-Raventós, 2018).

\section{ESR (Electron Spin Resonance)}

Nowadays, methods allowing immediate monitoring of free radicals alone and in reaction with a complex system (for example cells and tissues) are very important and widely used (Burlaka et al., 2018; Bukhari et al., 2018; Borbat et al., 2001). These methods mainly include ESR and electromagnetic spin resonance, also called electron paramagnetic resonance spectroscopy, EPR. Not only most complex food samples (Gardner et al., 1999) but also cosmetics or biological pharmaceutical samples are analyzed by ESR (Yamaguchi et al., 1999; Zang et al., 2017). This method is specific to the detection of unpaired electron species and it has an incomparably higher detection sensitivity than the previous spectrophotometric methods (Davies, 2016; Li et al., 2016; Yu and Cheng, 2008).

ESR uses microwave spectroscopy to detect spin state changes in substances containing unpaired electron spins (paramagnetic substrate). Spin state changes can be induced by microwaves with several milliwatts of energy when the substrate is placed in a magnetic field with 3480 gausses at the frequency of $9.5 \mathrm{GHz}$ (Figure 11) (Behzadnezhad et al., 2018). The resonance conditions directly depend on parameters such as the Planck's constant (h), frequency $(\nu)$ and the type of magnetic field $(H)$ and on the Bohr magneton ( $\beta$, equation 16) (Kleschyov et al., 2007).

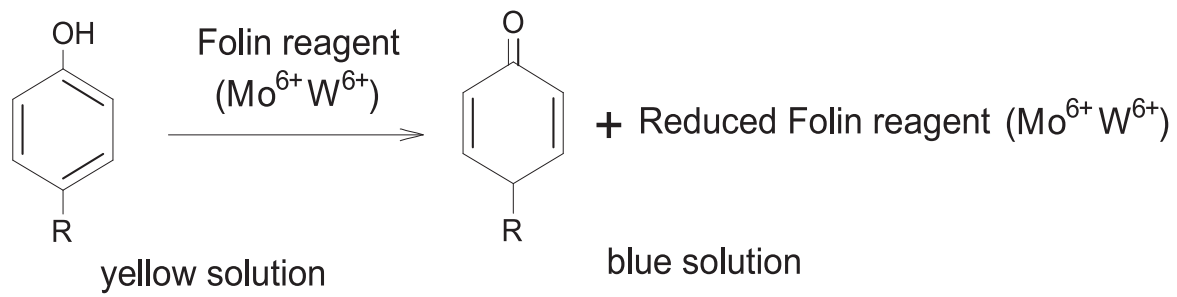

Fig. 10. Reaction of FC reagent with sample containing a hydroxyl group. 


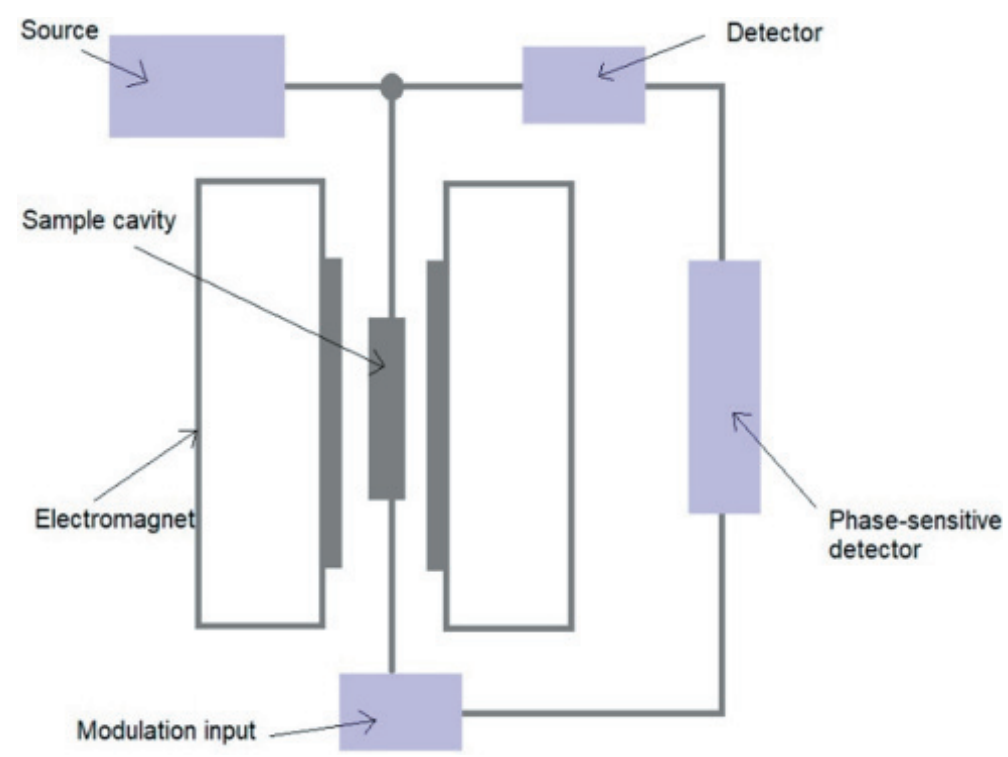

Fig. 11. Electron Spin Resonance apparatus.

$$
\mathrm{h} \nu=g \beta H
$$

Detection runs only with paramagnetic particles. Moreover, the presence of genetically active nuclei can also be observed in the spectrum (Davies, 2016).

At present, EPR spectroscopy has become a trend in antiradical activity determination in organosulfur compounds containing a sulfur-hydrogen bond (Jiang et al., 2018), phenolic compounds (Gardner et al., 1999; Okazaki and Takeshita, 2018), metal ions or tocopherol analogues (Sakurai et al., 2019). In case of thiol-containing compounds, several assays can be used, such as TEAC (more detailed in the text above) or frequent assays for the reduction of $\mathrm{Cu}^{2+}$ ions to $\mathrm{Cu}^{+}$by thiol compounds. In case of phenolic compounds, Okazaki et al. (2018) associated ESR with DMPO (5,5-dimethyl-1-pyrroline N-oxide) trapping and degradation by UV radiation while its adducts are quenched with phenols such as catechol, hydroquinone and resorcinol dissolved in a polar solvent (Okazaki and Takeshita, 2018).

\section{Discussion}

Antioxidant activity of substances can be studied by electron or hydrogen transfer methods. Determination of antioxidant activity should not be evaluated only by one test only because every method is relatively specific and it characterizes the antioxidant activity of pure substances and mixtures by its own mechanism of action; e.g. by scavenging of synthetic radicals, donation/acceptance of electrons or hydrogen atoms between antioxidants and oxidants or through the redox properties of substances or mixtures that are determined.
In the radical scavenging methods, reaction time of an antioxidant with a radical or with reagent varies considerably in various studies but it is usually in minutes (ABTS - $6 \mathrm{~min}$, DPPH - $30 \mathrm{~min}$, etc.). Reactivity depends on the structure of substrate molecules (inducing effects of substitutes and active groups present, steric hindrances), but also on solvent polarity, applied temperature and $\mathrm{pH}$ during the working assay and characteristics of reactive species. The fastest, simplest and cheapest method compared to others is the DPPH method (Alam et al., 2013). It has a widespread application in measuring antioxidant potential of beverages of fruit and vegetable origin, wheat grains, brans, edible vegetable seed oils, ascorbic acid, tocopherol and polyhydroxyaromatic compounds. This method is suitable for the analysis of substances dissolved in polar as well as non-polar solvents since the synthetic radical is dissolved in ethanol or methanol (Kedare and Singh, 2011). Other methods applicable to lipophilic and hydrophilic substances include the CB, TOSC and ABTS methods. The DMPD method is specific for potential lipophilic antioxidants testing and FC method for hydrophilic potential antioxidants (Apak et al., 2018).

Methods mentioned in the previous paragraph (DPPH, CB, ABTS, FC) belong to the spectrophotometric assays because they measure the absorbance of samples. In this work, methods based on the redox properties are also described. First, DMPD assay in which DMPD color is reduced. Second assay is FRAP in which ferric ions are reduced to ferrous ions and CUPRAC method using the reduction of copper from the oxidation number +2 to +1 (Gupta, 2015). Each method has its advantages and disadvantages and they can be modified for better application; 
however, these modifications represent an increase in either operating or equipment costs. Currently preferred methods applicable to hydrophilic and lipophilic antioxidants include DPPH, CB, TOSC and ABTS assay. In 2017, $0.17 \%$ of all manuscripts published in journals (Scimago Journal \& Country Rank) contained keywords DPPH, Folin-Ciocalteu assay or ABTS in the abstracts. According to Thaipong et al. (2006), it is very important to pay attention to the time and cost of assay necessary to determine the required parameters. A disadvantage of the ORAC method is its expensive work mechanism, whereas in the FRAP, ABTS and DPPH assays commonly available optical instruments are applied for measuring of light intensity relative to wavelength. Extra advantage of ABTS and FRAP assay is the rapid reaction of reagents with the sample to be analyzed; while the reaction in DPPH and ORAC methods are much slower. The FRAP test is characterized by its high ability to reproduce and repeat. TOSC and ORAC assays can be used for complex biological samples such as fluids and tissues. According to the study of Franzoni et al. (2017), the TOSC method is unique as it enables evaluating antioxidant potential of substances in the range of $\mu \mathrm{M}$.

\section{Conclusions}

The review of relevant assays for antioxidant activity determination in various substances from 1985 to the present is provided. Classification and characteristics of antioxidant assays were included. Each assay has its own mechanism of action such as color change during the reaction (DMPD, CB, ABTS, FC, DPPH, FRAP, CUPRAC), disappearance of luminescence (TRAP, ORAC), formation of ethylene (TOSC) or absorption of electromagnetic radiation (ESR). Then, the advantages and disadvantages of various antioxidant assays were compared by summarizing various characteristics of their application methods.

Reproduction of the results in different laboratories is crucial. It is most preferred to combine several methods for antioxidant activity determination. Thus, the range of methods for analyzing the properties of potential antioxidants can be expanded leading not only to the development of improved methods but also to more successful implementation of different analytical mechanisms in antioxidant substances and mixtures.

\section{Acknowledgements}

Support of the National Grant Agency, project No. APVV-16-0088, as well as VEGA 1/0012/19 are greatly acknowledged.

\section{References}

Abramovič H, Grobin B, Ulrih NP, Cigić B (2018) Journal of Chemistry 2018: 9 pages.

Ainsworth EA, Gillespie KM (2007) Nature Protocols 2 (4): 875-877.

Akar Z, Burnaz NA (2019) LWT 112: 108212.

Alam MN, Bristi NJ, Rafiquzzaman M (2013) Saudi Pharmaceutical Journal 21 (2): 143-152.

Al-Farsi M, Al-Amri A, Al-Hadhrami A, Al-Belushi S (2018) Heliyon 4 (10): e00874.

Alshaal S, Karabet F, Daghestani M (2019) Analytical and Bioanalytical Chemical Research 6: 97-110.

Apak R, Capanoglu E, Shahidi F (2018) Measurement of Antioxidant Activity and Capacity: Recent Trends and Applications. John Wiley \& Sons, USA.

Apak R, Güçlü K, Özyürek M, Celik SE (2008) Microchemica Acta 160 (4): 413-419.

Askin H, Yilmaz B, Gulcin I, Taslimi P, Bulut S, Yildiz M, Kandemir N (2018) Indian Journal of Pharmaceutical Sciences 80 (5): 802-812.

Behzadnezhad B, Behdad N, Mcmillan AB (2017) United States Patent Application Publication 2018/0340999 A1.

Benzie IFF, Strain JJ (1999) Methods in Enzymology 299: $15-27$.

Berker KI, Ozdemir Olgun FA, Ozyurt D, Demirata B, Apak R (2013) Journal of Agricultural and Food Chemistry 61 (20): 4783-4791.

Borbat PP, Costa-Filho AJ, Earle KA, Moscicki JK, Freed JH (2001) Science 291: 266-269.

Bortolomeazzi R, Sebastianutto N, Tonioolo R, Pizzariello A (2007) Food Chemistry 100 (4): 1481-1489.

Bukhari MH, Batool S, Raza DY, Bagasra O, Rizvi A, Shah A, Sultan T (2018) Electromagnetic Biology and Medicine 37 (3): 1-6.

Burlaka AP, Vovk AV, Burlaka AA, Gafurov MR, Iskhakova KB, Lukin SN (2018) BioMed Research International: 4848652.

Burnaz NA, Küçük M, Akar Z (2017) Journal of Chromatography B, 1052: 66-72.

Celik SE, Asfoor A, Apak R (2019) Journal of Agricultural and Food Chemistry 67 (29): 8279-8289.

Chiavaroli V, Giannini C, De Marco S, Chiarelli F, Mohn A (2011) Redox Report 16: 101-107.

Choy CKM, Benzie IFF, Cho P (2000) Biochemistry and Molecular Biology 41 (11): 3293-3298.

Davies MJ ((2016) Methods 109: 21-30.

Denardin CC, Hirsch GE, Rocha RF, Vizzotto M, Henriques AT, Moreira JCF, Guma F, Emanueloli $\mathrm{T}$ (2015) Journal of Food and Drug Analysis 23 (3): 387-398.

Drouet S, Doussot J, Garros L, Mathiron D, Bassard S, Favre-Réguillon, Molinié R, Lainé Éric, Hano Christophe (2018) Molecules 23 (10): 2594.

Everette JD, Bryant QM, Green AM, Abbey Y, Wangila GW, Walker R (2010) Journal of Agriculture and Food Chemistry 58 (14): 8139-8144.

Farajzadeh M, Abbaspour MA, Mogaddama MRA, Mogaddam A, Alizadeh Nabil AAAN (2016) Analytical and Bioanalytical Chemical Research 3: 239-251.

Ferrante AA, Martins IS, Silva LA, Percário S, Ferreira MES (2019) Australian Journal of Basic and Applied Sciences 13 (3): 19-22. 
Floegel A, Kim D, Chung SJ, Koo SI, Chun OK (2011) Journal of Food Composition and Analysis 24: 1043-1048.

Franzoni F, Federighi G, Fusi J, Agosta V, Cerri E, Banducci R, Petrocchi A, Bernardi R, Innocenti A, Pruneti C, Daniele S, Pellegrini S, Martini C, Scuri R, Galetta F (2017) Archives Italiennes de Biologe 155: $1-10$.

Gardner PT, McPhail DB, Crozier A, Duthie GG (1999) Journal of Science and Food Agriculture 79: 1011-1014.

Garrett AR, Murray BK, Robison RA, O’Neill KL (2010) Advanced protocols in oxidative stress 2: 251-262.

Goosen NJ, Ooshuizen D, Stander MA, Dabai AI, Pedavoah MM, Usman GO (2018) South African Journal of Botany 119: 11-16.

Granato D, Shahidi F, Wrolstad R, Kilmartin P, Melton LD, Hidalgo FJ, Miyashita K, Camp J, Alasalvar C, Ismail AB, Elmore S, Birch GG, Astley SB, Pegg R, Zhou P, Finglas P (2018) Food Chemistry 264: 471-475.

Gupta D (2015) International Journal of Pharmaceutical Sciences and Research 6 (2): 546-66.

Haida Z, Hakiman M (2019) Food Science \& Nutrition 7 (5): 1555-1563.

Holtz RW (2009) Skin Aging Handbook: In Vitro Methods to Screen Materials for Anti-aging Effects. William Andrew, Norwich NY.

Huang D, Ou B, Prior RL (2005) Journal of Agricultural and Food Chemistry 53(6): 1841.

Huda-Faujan N, Norrakiah AS, Babji AS (2009) African Journal of Biotechnology 8 (3): 484-489.

Jiang J, Zang S, Li D, Wang K, Tian S, Yu A, Zhang Z (2018) Talanta 184: 23-28.

Jiang Y, Rakesh KP, Alharbi NS, Vivek HK, Manukumar HM, Mohammed YHE, Qin H (2019) Bioorganic Chemistry 89: 103015.

Joseph NM, Sabharwal M, Shashi A, Mahor A, Rawal S (2018) International Journal of Pharmaceutical Sciences and Research 1: 1-11.

Kamer G, Demirata B, Bayraktar R, Ozyurt D, Apak R (2019) Analytical Methods 14.

Kedare SB, Singh RP (2011) Journal of Food Science and Technology 48 (4): 412-422.

Kimáková T, Baranovičová I (2015) Léčivá síla antioxidantú. Príroda, s.r.o, Bratislava.

Klaunig JE, Wang Z (2018) Current Opinion in Toxico$\operatorname{logy} 7: 116-121$.

Kleschyov AL, Wenzel P, Munzel T (2007) Journal of Chromatography B: 851 (1, 2), 12-20.

Koleva II, Niederländer H, Beek TA (2000) Analytical Chemistry 73 (14): 3373-3381.

Lachowicz S, Oszmiański J, Wiśniewski R (2018) European Food Research and Technology 244: 1269-1280.

Lamuela-Raventós RM (2018) Measurement of Antioxidant Activity and Capacity: Recent Trends and Applications. John Wiley \& Sons, USA.

Li D, Jiang J, Han D, Yu X, Wang K, Zang S, Lu D, Yu A, Zhang Z (2016) Analytical Chemistry 88: 3885-3890.

Li XY, Wang ZY, Wang L, Walid E, Zhang H (2012) International Journal of Molecular Science 13 (5): 5801-5817.

Lichtenthäler R, Marx F (2003) European Food Research Technology 216: 166-173.

Lim S, Choi A-H, Kwon M, Joung E, Shin T, Lee S, Kim N, Kim H (2019) Food Chemistry 278: 178-184.
Lobo V, Patil A, Chandra N (2010) Pharmacognosy Reviews 4 (8): 118-126.

Ma H, Liu T, Li J, Mingya D, Gao X, Chang Y (2019) Journal of Chromatography A 1593: 147-155.

Martín J, Kuskoski EM, Navas MJ, Asuero AG (2017) Flavonoids - From Biosynthesis to Human Health: Antioxidant Capacity of Anthocyanin Pigments. BoD - Books on Demand, Germany.

Mellado-Ortega E, Zabalgogeazcoa I, Aldana B, Arellano JB (2017) Analytical Biochemistry 519: 27-29.

Minussi RC, Rossi M, Bologna L, Cordi L, Rotilio D, Pastore G, Durán N (2003) Food Chemistry 82 (3): 409-416.

Moran-Palacio EF, Zamora-Álvarez LA, StephensCamacho NA, Yánez-Farías GA, Virgen-Ortiz A, Martínez-Cruz O, Rosas-Rodríguez JA (2014) Tropical Journal of Pharmaceutical Research 13 (9): 1487-1493.

Moukette BM, Pieme CA, Njimou JR, Biapa CP, Marco B, Ngogang JY (2015) Biological Research 48(1): 15.

Munialo CD, Naumovski N, Sergi D, Stewart D, Mellor DD (2019) 54 (5): 1448-1459.

Murauer A, Bakry R, Schottenberger H, Huck C, Ganzera M (2017) Analytica Chimica Acta 963: 136-142.

Nijhawan P, Arora S (2019) Obesity Medicine 15: 100-125.

Obón JM, Castellar R, Cascales JA, Fernándey-Lópey JA (2005) Food Research International 38 (8): 843-845.

Ojha K, Dubey S, Chandrakar J, Minj RA, Dehariya R, Dixit AK (2018) Research Journal of Life Sciences, Bioinformatics, Pharmaceutical and Chemical Sciences 4 (6): 707.

Okazaki S, Takeshita K (2018) Applied Magnetic Resonance 49 (8): 881-892.

Ononamadu C, Ihegboro GO, Owolarafe K, Salawu K, Fadilu M, Eyeigwe OC, Oshobu ML, Nwachukwu FC (2019) Analytical and Bioanalytical Chemical Research 6: 431-439.

Ordoudi SA, Tsimidou MZ (2006) Journal of Agricultural and Food Chemistry 54 (5): 1663-1671.

Oribayo OO, Owolabi MA, Ukpo GE, Shode FO (2018) Tropical Journal of Natural Product Research 2 (1): $18-22$.

Pérez-Burillo S, Rufián-Henares JA, Pastoriza S (2018) Food Chemistry 239: 1263-1272.

Pérez-Jiménez J, Saura-Calixto F (2008) International Journal of Food Science \& Technology 43 (1): 185-191.

Pisoschi AM, Negulescu G (2011) Biochemistry \& Analytical Biochemistry 1 (1).

Prieto MA, Vázquez JA, Murado M (2015) Food Chemistry 167 (15): 299-310.

Prior RL (2015) Journal of Functional Foods 18 (B): 797-810.

Re R, Pellegrini N, Proteggente A, Pannala A, Yang M, Rice-Evans C (1999) Free Radical Biology and Medicine 26 (9, 10): 1231-1237.

Regoli F (2000) Aquatic Toxicology 50 (4): 351-361.

Rodriguez-Nogales J, Vila-Crespo J, Gómez M (2011) Food Chemistry 129: 1800-1805.

Sakurai Y, Yamaguchi T, Ando K, Kuwabara K, Nakajima H, Morimoto C, Yoshikawa S, Niwa M, Miyake Y, Kanaori K, Nakajim A, Tajima K (2019) Bulletin of Chemical Society of Japan 92 (7): 1218-1225.

Sánchez-Rangel JC, Benavides J, Heredia JB, CisnerosZevallos L, Jacobo-Velázquez (2013) Analytical Methods 5 (21): 5990-5999. 
Schaich KM, Tian X, Xie J (2015) Journal of Functional Foods 18 (B): 782-796.

Seesom C, Jumepaeng T, Luthria DL, Chanthai S (2018) Journal of Food Health and Bioenvironmental Science 11 (2): 28-37.

Shalaby A (2013) African Journal of Pharmacy and Pharmacology 7 (10): 528-539.

Shekhar TC, Anju G (2014) American Journal of Ethnomedicine 1 (4): 244-249.

Shi S, Guo K, Tong R, Liu Y, Tong C, Peng M (2019) Food Chemistry 288: 215-220.

Singh S, Singh RP (2008) Food Reviews International 24 (4): 392-415.

Singleton VL, Orthofer R, Lamuela-Raventos RM (1999) Methods Enzymol. 299: 152-178.

Sotto AD, Checcon P, Celestino I, Locatelli M, Carissimi $\mathrm{S}$, Angelis MD, Rossi V, Limongi D, Toniolo Ch, Martinoli L, Giacomo SD, Palamara AT, Nencioni L (2018) Oxidative Medicine and Cellular Longevity 2018: 1-14.

Sundararajan R, Ilengesan R (2018) Free Radicals and Antioxidants 8 (1): 55-61.

Thaipong K, Boonprakob U, Crosby K, CisnerosZevallos L, Hawkins Byrne D (2006) Journal of Food Composition and Analysis: 19 (6, 7): 669-675.

Torre A, Henderson T, Nigam PS, Owusu-Apenten RK (2015) Food Chemistry 174: 119-123.

Van Den Berg R, Bast A (1999) Food Chemistry 66 (4): 511-517.

Wan HC, Sultana B, Nigam PS, Owusu-Apenten R (2018) Beverages 4 (3): 58.

Wayner DD, Burton GW, Ingold KU, Locke S (1985) FEBS Lett. 187: 33-37.
Wong C, Li H, Cheng K, Chen F (2006) Food Chemistry 97 (4): 705-711.

Yadav A, Kumari R, Yadav A, Mishra JP, Srivastava S, Prabha S (2016) Research of Environmental and Life Science 9 (11): 1328-1331.

Yamaguchi F, Yoshimura Y, Nakazawa H, Ariga T (1999) Journal of Agricultural and Food Chemistry 47: 2544-2548.

Yan X, Murphy BT, Hammond GB, Vinson JA, Neto CC (2002) Journal of Agriculture and Food Chemistry 50 (20): 5844-5849.

Yeo JD, Shahidi F (2019) Journal of Agricultural and Food Chemistry 67: 7526-7529.

Yeum KJ, Russell RM, Krinsky NI, Aldini G (2004) Archives of Biochemistry and Biophysics 430 (1): 97-103.

Yu LL, Cheng Z (2008) Molecular Nutrition \& Food Research 52: 62-78.

Zablocka A, Sokolowska A, Macala J, Bartoszewska M, Mitkiewicz M, Janusz M, Wilusz T, Polanowski A (2019) International Journal of Peptide Research and Therapeutics: $1-10$

Zang S, Tian S, Jiang J, Han D, Yu X, Wang K, Li D, Lu D, Yu A, Zhang Z (2017) Food Chemistry 221: 1221-1225.

Zhong Y, Shahidi F (2015) Food Science, Technology and Nutrition: 287-333.

Zhong Y, Shahidi F (2015) Handbook of antioxidants for food preservation: methods for the assessment of antioxidant activity in foods. Woodhead Publishing, UK. 